\title{
A Study of Psychiatric Morbidity in Patients Attending the Medical Gastro Enterology Unit in a Teaching Hospital
}

\author{
Arifuddin Ahmed ${ }^{1}$, Rajini Tenali ${ }^{2 *}$, Faheemuddin Naveed ${ }^{3}$, \\ Ramakrishna Podaralla ${ }^{4}$
}

\section{ABSTRACT}

The World Health Organization defines health a state of complete physical, mental and social wellbeing and not merely the absence of disease or infirmity. This includes the capability to be productive both socially and economically. The functional gastrointestinal disorders (FGIDs) are a heterogenous group of chronic conditions that are considered to have no structural or biochemical abnormalities that account for the symptoms. They are supposed to originate from malfunction of the gut with respect to the nervous mis perception. In these cases, anxiety and or depression could be present mainly in the 'state' and or 'current' form, reactive to the symptoms. Aim: Descriptive study to assess the socio demographic profile of patients with gastrointestinal disorders. To study the psychiatric morbidity in gastrointestinal disorder patients attending gastrointestinal clinics. Objectives: To study the relationships between factors attributable to gastrointestinal disorders and psychiatric morbidity. To study the effectiveness of GHQ as a screening instrument for psychiatric morbidity in gastrointestinal patients. Sample: 52 patients with gastrointestinal problems of all kinds who attended OPD with age group of 15-65 years. Methods: General Health Questionnaire (GHQ) standardized tool was used. Results: Married patients had higher GAD and MDD compared to unmarried patients. Unemployed and retired people had higher rates of GAD and MDD compared to employ. Students with GI disease had no psychiatric morbidity. All subscales of GHQ showed correlation significantly.

Keywords: Psychiatric Morbidity, Gastrointestinal Disorders, General Health

The World Health Organization defines health a state of complete physical, mental and social wellbeing and not merely the absence of disease or infirmity. This includes the capability to be productive both socially and economically. In the last 100 years, several spectacularly successful

\footnotetext{
${ }^{1}$ Deccan College of Medical Sciences, Hyderabad, Telangana, India

${ }^{2}$ Assistant Professor, Deccan College of Medical Sciences, Hyderabad, Telangana, India

${ }^{3}$ Deccan College of Medical Sciences, Hyderabad, Telangana, India

${ }^{4}$ Deccan College of Medical Sciences, Hyderabad, Telangana, India

*Responding Author

(C) 2016, A Ahmed, R Tenali, F Naveed, R Podaralla; licensee IJIP. This is an Open Access Research distributed under the terms of the Creative Commons Attribution License (http://creativecommons.org/licenses/by/2.0), which permits unrestricted use, distribution, and reproduction in any Medium, provided the original work is properly cited.
} 


\section{A Study of Psychiatric Morbidity in Patients Attending the Medical Gastro Enterology Unit in a Teaching Hospital}

public health measures have significantly increased life expectancy in developed countries, including control of infectious diseases with immunization and other strategies, reduced infant and child mortality, safer food and work places, anti-smoking measures, and improved motor vehicle safety. Subsequently, the attention of population health experts has turned to preventing or controlling chronic diseases, and their impact on quality of life and work productivity. A focus of public health research is to define the social context of misery and disease, so that strategies can be developed and applied that prevent or treat the problem at the population level.

From times immemorial, alongside structural diseases of the gastrointestinal tract are the diseases that have produced very similar and multiple symptoms of gastrointestinal disease-pain, nausea, vomiting, bloating, diarrhoea, constipation, difficult passage of food or faeces, etc. When a patient approaches a trained physician with any or more of the aforementioned symptoms, the physician approaches the illness as due to either an infectious or inflammatory or neoplastic or a structural (anomalies) aetiology and only if he draws a blank on this does he proceed towards making a diagnosis of a "functional" disorder. These disorders are enigmatic to say the least and hence less amenable to therapy.

The functional gastrointestinal disorders (FGIDs) are a heterogenous group of chronic conditions that are considered to have no structural or biochemical abnormalities that account for the symptoms. Symptoms in FGID are supposed to originate from malfunction of the gut with respect to the nervous mis perception. These conditions are important to public health because they are remarkably common, can be disabling and induce a major economic brden. The best known of these conditions is the irritable bowel syndrome (IBS).

The descriptions of gut dysfunction have been discovered in the most primitive of texts as well. Papyrus records show that the Egypatians used a lot of herbal and plant concoctions to deal with conditions like indigestion and constipation and also seemed to recognize stress as an aetiological factor in their causation; they established sanitariums where "dream therapy" and healing with sacred medicinal waters was practiced. Plato, Aristotle and Hippocrates prescribed "holism" as a therapeutic option for this about 3,400 years ago the concept was later carried forward by Maimondes- a Jewish philosopher and physician-here the individual was views as whole a not only with respect to the diseases part(1).

The French philosopher Descartes proposed a separation of the mind and the body which was metaphorical with the harmonized separation of the Church and the state. This dualistic approach gave birth to the biologically reductionistic theory to the causation of disease - where the effort was to identify a single biological entity and this had an influence on the view of illness and health for at least three hundred years. This marginalized the central nervous system as a plausible cause for illness and disease for the next three hundred years. The first reliable

(C) The International Journal of Indian Psychology, ISSN 2348-5396 (e) | ISSN: 2349-3429 (p) | 224 


\section{A Study of Psychiatric Morbidity in Patients Attending the Medical Gastro Enterology Unit in a Teaching Hospital}

description for irritable bowel syndrome was suggested by Powell- an English physician who recognised the basic constellation of " abdominal pain, derangement of digestion (like symptoms) and flatulence” in 1818 (2).A paradigm shift from the reductionistic concept of Descrates, however took more than 300 years; by the end of the 1970's, a more integrated, holistic concept of illness and disease was enunciated-the biopsychosocial model of health and disease: This allowed for symptoms to be both physiologically multi-determined and modifiable. These developments led to the enunciation of the Rome criteria for classification of the functional gastrointestinal disorders.

Anxiety and depression represent a common feature in patients affected by gastrointestinal diseases $(3,4)$.In some cases as in patients with functional gastrointestinal disorders, anxiety and depression are present particularly as a personality trait (5).Recent studies showed that in these subjects, medical consultation is necessary because of the 'health care seeking behavior' strictly related to the anxious trait, more than to the organic symptoms $(6,7)$.In this case, the socioeconomic impact resulting from consultations with several gastroenterologists and from undergoing clinical examinations and consumption of drugs, is very high (8).On the other hand, few information are at present available about anxiety and depression in patients in whom an organic cause for their symptoms has been found (4).In these cases, anxiety and/or depression could be present mainly in the 'state' and / or 'current' form, reactive to the symptoms (9),to the long-term diseases (4),to long term therapies and dietary restrictions (10),to the necessity of frequent medical control and to the reduction of the quality of life and of general well-being $(11,12)$.However, at present, few data about the prevalence of state and trait form of anxiety and of current depression are available in large sample of patients.

\section{REVIEW OF LITERATURE}

Psychiatric disorders are prevalent in medical practice, especially in primary care, where as many as one third of patients may suffer from one or more current diagnosable psychiatric disorders especially depressive and anxiety disorder (13). Among patients with functional gastrointestinal disorders, the rates of associated psychiatric disorders are even higher. In the case of IBS, $50 \%-90 \%$ of those seeking treatment have been found to also have comorbid lifetime psychiatric disorders, especially depressive and anxiety disorders in $15 \%$ to $48 \%$ among IBS patient samples(13), but also because of implications introduced by the presence of somatisation disorder for classification and understanding of IBS and probably also other functional disorders as well.

The relationship between the gut and the brain has been known since antiquity. That the gut is very responsive to changes in, and disturbances of mental functionins have been universally observed. The brain often speaks through the gut. 


\section{A Study of Psychiatric Morbidity in Patients Attending the Medical Gastro Enterology Unit in a Teaching Hospital}

The close links between the gastro-intenstinal system and the brain may manifest themselves clinically in a number of ways. Basically, there might be (a) A Primary psychiatric disorder which has a somatic symptom involving the gut, or alternatively (b) There might be a G.I disorder in whose etiology, course and prognosis mental functioning has a prominent role (psychosomatic disorder).

Amongst the former, the primary psychiatric disorders which have prominent G.I symptoms include the anxiety disorders, depression, the somatisation disorders, adjustment disorder, and less frequently, disorders like anorexia nervosa and bulimia nervosa among others.

Amongst the latter, some G.I disorders in which psychological factors play an important role include Duodenal ulcer, Gastric ulcer, Irritable colon, Mucous colitis, Pylorospasm, Regional Enteritis, Spastic colitis, and Ulcerative colitis. Apart from these, the symptoms of nausea and vomiting may very often have a psychological significance.

\section{GENDER, AGE, SOCIETY, CULTURE AND THE PATIENT'S PERSPECTIVE IN THE FUNCTIONAL GASTREOINTESTINAL DISORDERS:}

Sex, Gender and Gender Role (14) - Sex refers to a person's biological femaleness and maleness. While gender refers to the non-biological aspects of being male or female - in other words the societal and cultural expectations associated with feminity and masculinity. However it is a well known that the differences between the male and the female genders are due to environmental and biological interactions.

Gender and Epidemiology: Symptoms of FGID are quite prevalent in the community. The majority of these are more common in the female gender. Although one study (15)from US reported an equal prevalence between the two sexes, a majority have reported a female preponderance in the region of 2-3:1 $(16,17)$

Studies have demonstrated that the prevalence of functional esophageal and gastro duodenal disorders do not vary with gender (18).Female gender is associated with increased prevalence of delayed gastric emptying, lower tolerance of water-loading test in functional dyspepsia syndromes, on-pain associated symptoms of constipation, bloating and extra-intestinal manifestations(16,17).There is little evidence to suggest that the symptoms of functional dyspepsia worsen with menses but there is good evidence that suggests that the symptoms of IBS definably worsen with menstruation particularly in the luteal and menstrual phase $(18,19)$

Gender and Biological Factors: FGID's are best viewed as biopsychological disorders with dysregulation of the brain-gut axis (19), which results in alterations in visceral pain perception, autonomic function and central processing of visceral stimuli. Gender differences in these mechanisms have been evaluated extensively in irritable bowel syndrome.

Visceral pain perception: studies in male and female genders have shown no differences in the visceral perception of pain. There appears to be an effect of the female sex hormones on rectal 


\section{A Study of Psychiatric Morbidity in Patients Attending the Medical Gastro Enterology Unit in a Teaching Hospital}

sensitivity in women with irritable bowel syndrome. Rectal sensitivity was compared across the four phases (menstrual, follicular, luteal and pre-menstrual) of the menstrual cycle between healthy female volunteers and patients of irritable bowel syndrome. The thresholds for rectal sensitivity, distension induced rectal motility and rectal compliance were not found to be a lower during any phase of the cycle in healthy volunteers, however there was a definite lowering of perceptualtheresholds in the menstrual phase in patients with irritable bowel syndrome (20)

Gastrointestinal Motility: Studies have demonstrated that either shorter or equivalent gastrointestinal transit times in healthy males and healthy females $(21,22)$

Gender and Psychological Factors: Although there are many studies of psychological functioning in FGID, relatively few investigators have examined gender differences. The majority of studies have included a psychological evaluation and have been carried out in the general hospital setting and in GI outpatient clinics.

In general the findings of most studies suggest that patients with FGID who are seen in outpatient GI treatment settings have a high rates of a psychiatric disorder and psychological distress (between $40 \%$ and $60 \%$ ).In studies that have examined for gender differences in FDID, or reported on certain aspects of gender, relatively few studies have reported differences in psychological symptom scores between men and woman $(23,24)$

At present, there are relatively few studies that have examined gender differences in psychological symptoms in FGID, and there is no convincing evidence of any major differences between men and women with FGID.

\section{Gender and Social Factors:}

It is important to acknowledge that health and illness, including FGID, occur within a larger social context. Although there have been many studies evaluating the role of stress and abuse in FGID, there has been relatively little effort to date directed toward identifying other social factors that have been associated with FGID.A few social determinants that have been investigated in FGID include life stressors (including history of sexual, physical, and emotional labuse),early life experiences (including gender role socialization) social support, and social factors that have been assessed by quality of life scales.

\section{Gender and Treatment Response:}

Psychological Treatment: Studies have been powered to examine different response patterns between men and women, and many studies have recruited more women than men, reflecting gender differences in health treatment settings. Patients had a good treatment response to hypnotherapy ,there was greater overall improvement in women compared to men.

\section{Pharmacological Treatment:}

Males have been found to benefit more with pharmacological therapy. There is evidence to suggest that gender-related differences may exist with respect to response to pharmacologic therapy, although relatively small numbers of men have been studied compared with women. 


\section{A Study of Psychiatric Morbidity in Patients Attending the Medical Gastro Enterology Unit in a Teaching Hospital}

Age:

In regard to the functional oesophageal disorders, the prevalence of most of these disorders the prevalence of most of these disorders decreases with age. Specifically, globus, rumination syndrome, and self-reported functional chest pain are all more common in younger people $(16,25,26)$. The prevalence of heartburn overall is similar among people aged 25-74 (25). The prevalence of dysphagia in one study increased with age, most notably in participants in the 6575 yrs old category. The prevalence of dyspepsia decreases with age $(27,28)$. Young people are slightly more likely to report aerophagia than older people. Vomiting decreases with age (15) The prevalence of IBS gradually decreases with advancing age,(29,30,31). Functional diarrhea and chronic functional abdominal pain appear to decrease with age (16) Fecal incontinence has been extensively studies and increases with age $(16,29,32)$

\section{Society:}

Several societal myths associated with FGID, I particular IBS, persist today symptoms are trivial or unimportant; symptoms are all in the person's head IBS is simply caused by stress; IBS is a psychiatric disorder; nothing can help persons with IBS; If pain is severe there must be an organic cause; patients with IBS may benefit from the 'sick role' and people with IBS are difficult patients (33).

\section{From a Research Perspective:}

Studies to identify positive aspects of patient-provider interactions that improve outcome should be performed and include recognition of the patient's perspective, cultural and gender sensitivity, and implementation into patient care programs.

Studies using quantitative and qualitative methods are needed to better understand the patient's illness experience and his or her views of the health care system.

Studies of varied populations around the world should be performed with appropriate tools to measure cultural and societal influences.

Studies evaluating sufficient numbers of men with IBS, and also making comparisons between healthy men and women are need to determine if gender differences in FGID are disease specific.

\section{Aim:}

1. A descriptive study $t$ oassess the socio demographic profile of patients with gastrointestinal disorders.

2. To study the psychiatric morbidity in gastrointestinal disorders patients attending gastrointestinal clinics.

3. To screen for current psychiatric disorders in the sample using general health questionnaire.

\section{Objectives:}

1. To study the relationships between factors attributable to gastrointestinal disorders and psychiatric morbidity

2. To study the effectiveness of GHQ as a screening instrument for psychiatric morbidity in gastrointestinal patients.

(C) The International Journal of Indian Psychology, ISSN 2348-5396 (e) | ISSN: 2349-3429 (p) | 228 


\section{A Study of Psychiatric Morbidity in Patients Attending the Medical Gastro Enterology Unit in a Teaching Hospital}

\section{METHODOLOGY}

\section{Data Source:}

The present study was a cross sectional descriptive study, conducted at Deccan College of Medical Sciences and OHRC, Hyderabad.

\section{Sample:}

Cases consisted of 52 subjects between the ages of 15-65. No control group.

\section{Inclusion Criteria:}

1. Consenting patients in the age group of $15-65$,of either sex, presenting to the GI OPD of DCMS \& OHRC, irrespective of GI diagnosis

2. Symptom duration of 1 month or more

\section{Exclusion Criteria:}

1. Patients with any major systemic disorder (involving any system apart from GIT)

2. Patients with pre-existing diagnostic psychiatric disorder

3. Patient who have received psychotropic drugs or ECT within the last 3 months

4. Pregnancy

5. Malignancy

6. Drug dependency

7. Seizure disorders

\section{Operational Procedures:}

The Gastroenterologist would refer cases of GIT disorders to the investigator These subjects were then screened using the inclusion and exclusion criteria The Subjects so chosen, were explained the nature of the study Informed consent was then obtained from each subject Using the intake proforma, details about sociodemographic data, was collected Each subject was then given a non-structural clinical interview to arrive at a diagnosis. This diagnosis was corroborated with qualified clinician. Then each patient was administered with a 28 item general health questionnaire (GHQ)

\section{Description Of Tools Used:}

Intake Proforma: It was specially designed for study and it includes:

a) Socio demographic data

b) Gastrointestinal disorder duration \& diagnosis

c) Past illness

d) Physical examination

e) Psychiatric history and examination 


\section{A Study of Psychiatric Morbidity in Patients Attending the Medical Gastro Enterology Unit in a Teaching Hospital}

Master Score Sheet:

This was prepared to score the general health questionnaire (GHQ)

\section{Description of Scales:}

GENERAL HEALTH QUESTIONNAIRE:

Developed by David Goldberg at Institute of Psychiatry for use in London as a screening instrument in community settings, primary care and medical out patients. Now being used in many different countries/cultures and has been translated into 38 different languages. Derived from various existing scales, such as Cornell Medical Index. The original version consists of 60 items (GHQ-60).Shorter versions were subsequently developed (GHQ-30;GHQ-28 (with 4 sub scales) and GHQ-12)

\section{GHQ MEASURES:}

Focuses on breaks in normal functioning, rather than lifelong traits (cf.EPQ)

Concerns itself with two major classes of phenomenon Inability to carry out one's normal healthy functions. Appearance of new phenomena of a distressing nature.

The 28-item General Health Questionnaire is a shortened version of the 60-tem questionnaire. It is a self-administered instrument to screen for current psychiatric disorders in the general population. The questions are divided into 4 subscales (Somatic complaints, anxiety/insomnia, social dysfunction and severe depression)

\section{RESULTS}

Socio-Demographic results indicated as married 72.5\% $(\mathrm{n}=37)$, unmarried $21.6 \%(\mathrm{n}=11)$ widow $5.9 \%(n=3)$, Females constituting 52.9\% $(n=27)$ and $47.1 \%(n=24)$. Muslims were maximum consisting of $80 \%(n=41)$, Hindus comprising of $15.7 \%(n=8)$ followed by Christians $3.9 \%$ $(n=2)$. Unemployed people 43.1\% $(n=22)$, employed people consisting of $35.3 \%(n=18)$, followed by students $13.7 \%(n=7)$, Retired people $7.8 \%(n=4)$.

Socio economic status of the population in this study middle class consisting $64.7 \%(n=33)$. Low class people comprising 33.3\% $(n=17)$. High class people consisting of $2 \%(n=1)$. Urban population is maximum $82.4 \%(\mathrm{n}=42)$. Rural population $17.6 \%(\mathrm{n}=9)$

People suffering from APD were maximum consisiting of 66.7\% ( $\mathrm{n}=34)$, IBS 11.8\% ( $\mathrm{n}=6)$. Constipation \& GERD 9.8\% ( $n=5)$. GAD is slightly less, i.e $49 \%(n=25)$ than those who were not having any GAD which is about $51 \%(\mathrm{n}=26)$.

Depression $43.1 \%(n=22)$, which is less than those who were found to have no depression and it consists of about $56.9 \%(n=29)$. 


\section{A Study of Psychiatric Morbidity in Patients Attending the Medical Gastro Enterology Unit in a Teaching Hospital}

Somatoform disorder $9.8 \%(n=5)$ compared to those who were found to have no problem and which is maximum i.e $90.2 \%(n=46)$

\section{Sex Vs Gad:}

Females $55.6 \%$ Males $41.7 \%$. The values are not significant as the p value is 0.322

\section{Sex Vs Depression:}

Females $48.1 \%$ Males 37.5\%. The values are not significant as the p value is 0.443

\section{Sex Vs Somatoform Disorders:}

Females $96.3 \%$ Males $83.3 \%$. The values are not significant as the p value is 0.120

Marital Status Vs Generalised Anxiety Disorders:

Married people $56.8 \%$ unmarried people $9.1 \%$, widow $100 \%$. This is significant with p value 0.04

\section{Marital Status Vs Depression}

Married people $51.4 \%$ unmarried people $9.1 \%$, widow $66.7 \%$. This is significant with p value 0.032

\section{Marital Status Vs Somatic Complaints:}

Married people $89.2 \%$ unmarried people $90.9 \%$, widow $100 \%$. This is not significant with $\mathrm{p}$ value 0.829

\section{Religion Vs Generalised Anxiety Disorder:}

Christians 0\%, Hindus 37.5\%, Muslims 53.7\%. This is not significant as the p value is 0.259

\section{Religion Vs Depression:}

Christians 50\%, Hindus 25\%, Muslims 46.37\%. There was no significance ( $>>0.05 \%$ ) difference between groups.

\section{Religion Vs Somatoform Disorders:}

Christians 0\%, Hindus 25.0\%, Muslims 7.3\%. This is not significant as the p value is 0.273

Occupation Vs Generalised Anxiety Disorder:

Patients who are employed was $50 \%$, Retired $75 \%$ in students it was $0.0 \%$ and in unemployed $59.1 \%$. This is significant as the p value is 0.033

\section{Occupation Vs Depression:}

Employed people was $38.9 \%$, Retired $75 \%$, Students $0.0 \%$, unemployed $54.5 \%$. This is significant as the p value is 0.04

\section{Occupation Vs Somatoform Disorders:}

Employed people was 22.2\%, Retired 0\%, Students 0\%, unemployed 4.5\%. This is not significant as $\mathrm{p}=0.170$

Socio Economic Status Vs Generalised Anxiety Disorders:

Socioeconomic status high $100 \%$, Low socioeconomic status was $52.9 \%$, Middle $45.5 \%$. This is not significant as the $\mathrm{p}$ value is 0.519

(c) The International Journal of Indian Psychology, ISSN 2348-5396 (e)| ISSN: 2349-3429 (p) | 231 


\section{A Study of Psychiatric Morbidity in Patients Attending the Medical Gastro Enterology Unit in a Teaching Hospital}

Socio Economic Status Vs Depression:

Socioeconomic status high $0 \%$, Low socioeconomic status was $47.1 \%$, Middle $42.4 \%$. This is not significant as the p value is 0.647

Socio Economic Status Vs Somatoform Disorders:

Socioeconomic status high $0.0 \%$, Low socioeconomic status was $11.8 \%$, Middle $9.1 \%$. This is not significant as the $\mathrm{p}$ value is 0.904

Urban / Rural Vs Generalized Anxiety Disorder:

Rural population 33.3\%, Urban $52.4 \%$. This is not significant as the p value is 0.300

Urban / Rural Vs Depression:

Rural population $44.4 \%$, Urban $42.9 \%$. This is not significant as the ( $p>0.05$ )

\section{Urban / Rural Vs Somatoform Disorders:}

Rural population $22.2 \%$, Urban $7.1 \%$. This is not significant as the p value is 0.167

\section{GI Disease Vs Generalised Anxiety Disorder:}

APD 52.9\%, Constipation 20.0\%, GERD 0\%, IBS 100\%. This is significant as the p value is 0.008

\section{GI Disease Vs Depression:}

APD 32.4\%, Constipation 100\%, GERD 0\%, IBS 100\%. This is significant $(\mathrm{p}<0.005)$

\section{GI Disease Vs Depression:}

APD 14.7\%, Constipation 0\%, GERD 0\%, IBS 0\%. This is not significant as the p value is 0.597

\section{GI Disease Vs GHQ Scores:}

The GHQ somatic and GAD sub scales scores of patients with inflammatory bowel disease and Acid peptic disease are similar $(\mathrm{p}=0.269)$

The GHQ social dysfunction and depression subscale scores between IBS and APD are significantly different with $\mathrm{p}$ values of 0.036 and 0.016 respectively

The GHQ total score in APD is significantly ( $\mathrm{p}=0.015)$ lower than in IBS

\section{GHQ Score and Generalised Anxiety Disorder:}

The GHQ somatic sub scale score between GAD patients and people without any psychiatric morbidity is not significant ( $\mathrm{p}>0.05)$

The GHQ anxiety and insomnia, social dysfunction and depression subscales score higher in patients with GAD compared to the people without psychiatric morbidity $(\mathrm{p}<0.05)$

The GHQ total score between GAD patients and people without any psychiatric morbidity is higher $(\mathrm{p}<0.05)$

\section{GHQ And Depression:}

The GHQ somatic sub scale score between depression patients and people without any psychiatric morbidity is not significant $(\mathrm{p}>0.05)$

The GHQ anxiety and insomnia, social dysfunction and depression subscales score higher in patients with GAD compared to the people without psychiatric morbidity $(\mathrm{p}<0.05)$ 


\section{A Study of Psychiatric Morbidity in Patients Attending the Medical Gastro Enterology Unit in a Teaching Hospital}

The GHQ total score between depression and people without psychiatric morbidity is higher $(\mathrm{p}<0.05)$

\section{GHQ And Somatoform Disorders:}

The GHQ somatic and anxiety subscale scores are higher in somatoform patients than people without any psychiatric morbidity $(\mathrm{p}<0.05)$

The GHQ social dysfunction and depression subscales in somatoform patients and people without psychiatric morbidity is not significant ( $\mathrm{p}>0.05$ )

The GHQ total scores in somatoform patients and patients without psychiatric morbidity is not significant $(\mathrm{p}>0.05)$

\section{GHQ Vs Psychaitric Morbidity:}

All individuals subscales scores and total scores in people with psychiatric morbidity is higher than without morbidity $(\mathrm{p}<0.05)$

\section{DISCUSSION}

The present study was done at Owaisi Hospital and Research Centre, Hyderabad in its Gasteroenterology Clinic. The sample was collected by serial sampling, from patients attending the above mentioned dermatology clinics, between July and August 2008.Consenting patients in the age group of 15-65 years of either sex with symptom duration of 1 month or more were taken into the study. Patients were screened out for any major disorders, history of past psychiatric illnesses, malignancy and seizure disorders.

After obtaining the socio-demograohic data and details pertaining to the gastrointestinal illness, each subject was administered by non structural clinical interview to assess for psychiatric illness. The case was then discussed with a qualified psychiatrist and a diagnosis was given. Now the patients were administered the 28 item version of GHQ. The data so obtained was analyzed by statistical methods and results were complied.

\section{DEMOGRAPHIC FACTORS}

\section{Age:}

The frequency distribution of age in patients attending GI clinics shows a normal distribution with mean of 27 years.52.8\% of those patients were between the age groups of 20-29.Age of onset of illness and current age didn't have significant association $(p=0.761)$ with occurrence of psychiatric morbidity.

\section{Religion:}

About $80 \%$ of the patients were Muslims of the total sample, Hindus accounting for $15.7 \%$ only can be explained by the catchment area of Owaisi Hospital. No significant difference in psychiatric morbidity was seen between religions. 


\section{A Study of Psychiatric Morbidity in Patients Attending the Medical Gastro Enterology Unit in a Teaching Hospital}

\section{Sex:}

The sample consisted of $47.2 \%$ males and $52.9 \%$ females. No significant difference in psychiatric morbidity was seen between males and females.

\section{Marital Status:}

The frequency of married people was maximum (72.5\%), Unmarried patients had the least GAD and depression. Most patients who were widows had generalized anxiety disorder and major depressive disorder. About half of the married people had generalized anxiety disorder. Depression was seen in about $50 \%$ of the patients. The differences between the groups was significant for both GAD and depression $(\mathrm{p}<0.05)$

\section{Socio Economic Factors:}

Unemployed people are seen at the highest frequency in the sample at $43.1 \%$. This should be seen in the background that more people who presented were females specifically who were housewives. None of the students had GAD or MDD. unemployed persons and retired people had high rates of GAD and MDD. These findings were significant $(\mathrm{p}<0.05)$

A normal distribution is obtained for the socioeconomic class. Most of the population belonged to the middle social classes (64.7\%).This data is consistent with the catchment area of the hospital. Urban population accounted for $82.4 \%$ of the sample. No significant difference among the socio economic classes was seen for the prevalence of psychiatric morbidity.

About $80 \%$ of the patients were from an urban background. The finding shows area of the hospital. No significant difference among these groups was seen for occurrence of psychiatric morbidity.

\section{Gastrointestinal Disease Factors:}

Among people attending the GI clinic acid peptic disease accounted for the maximum proportion (66.7\%).Irritable bowel syndrome accounted for $11.8 \%$ of the clinic attendees. Other disorders included constipation and gastro esophageal reflux disease.GAD in APD patients was 52.9\% and in IBS patients was $100 \%$. This difference is significant $(\mathrm{p}<0.05)$.Depression in APD patients was $32.4 \%$ and in IBS patients was $100 \%$.This difference is significant $(\mathrm{p}<0.05)$

\section{Psychiatric Morbidity:}

About half of the patients with GI disease had GAD. Major depression was seen in $43.1 \%$ somatoform disorders were seen in $9.8 \%$ of the patients. $25 \%$ of the sample didn't have any psychiatric morbidity.GHQ scores were significantly higher in generalized anxiety disorder and in depressed patients. The anxiety, social dysfunction, depression subscales of the GHQ also showed significantly higher scores in GAD \& MDD.As expected, GHQ scores though not significantly higher in patients with somatoform disorders, they were higher in the somatic complaints subscale of the GHQ. Scores of GHQ total score and that of its individual subscales was significantly higher for patients with psychiatric morbidity than those without. 


\section{A Study of Psychiatric Morbidity in Patients Attending the Medical Gastro Enterology Unit in a Teaching Hospital}

\section{SUMMARY \& CONCLUSIONS}

Married patients had higher GAD and MDD compared to unmarried patients. Unemployed and retired people had higher rates of GAD and MDD compared to employed people. Students with GI disease had no psychiatric morbidity. GHQ scores were higher in GAD and MDD. Especially the anxiety, social dysfunction and depression subscales of the GHQ. Somatic complaints subscale of GHQ showed higher scores in patients with somatoform disorders. GHQ scores were higher for GI patients with psychiatric morbidity. All subscales of the GHQ showed this correlation significantly.

\section{LIMITATIONS OF THE STUDY}

The psychiatric morbidity was assessed clinically. A semi structured diagnostic interview would have yielded more unbiased results. It was a cross sectional study and the individuals were not followed up. The generalization of the findings is limited because of the small sample. Keeping the above limitations in view, the following suggestions are made. A comparative study using the same methodology would further enhance the value of these findings. The findings of the study can be replicated with a large sample.

\section{IMPLICATIONS OF THE STUDY}

The study highlights the significant occurrence of psychiatric illnesses in patients attending the gastro intestinal disorder clinic. There is a need to raise the awareness about mental disorders in the community and among health professionals, and to improve access to appropriate mental health care. Organizations of health care services should take into account the needs of this special population and should emphasize professional training for the correct assessment and treatment of mental disorders.

\section{No Conflict Of Interest}

\section{REFERENCES}

1. Ackerneckt EH, ed. A short history of medicine 1982. JHU press; 304

2. Drossman DA. Psychosocial and psychophysiological mechanisms of GI illness. In Kirsner JB ed. The growth of gastrointestinal knowledge in the $20^{\text {th }}$ century. Philedelphia. Lee Febiger 1993;41;432

3. Levy RL, Olden KW, Naliboff BD et al. Psychosocial aspects of functional gastrointestinal disorders. Gastroentrol 2006; 130: 1447-58.

4. Van Kerkhoven LAS, Van Rossum LG, Van Oijen MGH et al. Anxiety, Depression and psychotropic medication use in patients with persistent upper and lower GI symptoms. Aliment Pharmacol Ther 2005;25:1001-6 


\section{A Study of Psychiatric Morbidity in Patients Attending the Medical Gastro Enterology Unit in a Teaching Hospital}

5. Addolorato G, Marsigli L, Capristo E. Caputo F, Dall’Aglio C, Baudanza P. Anxiety, depression: a common feature of health care seeking patients with irritable bowel syndrome and food allergies. Hepatogastroenterol 1998; 45:1559-64.

6. Smith RC, Greenbaum DS, Vancouver JB et al. Psychosocial factors are associated with health care seeking than diagnosis in IBS. Gastroenterol 1990;98: 293-301

7. Koloski N, Tally NJ, Boyce PM, Predictors of health care seeking for Irritable bowel syndrome and nonulcer dyspepsia: critical review of the literature on symptom and psychosocial factors. Am J Gastroenterol 2001; 96: 1340-9.

8. Maxion -Bergemenn S, Thielecke F, Abel F, Bergemann R. Costs of Irritable Bowel Syndrome in UK and US. Pharmacoeconomics 2006; 24:21-37.

9. Addolorato G, Capristo E,Stefanini GF, Gasbarini G. Inflammatory bowel disease: a study of the association between anxiety and depression, physical morbidity and nutritional status. Scand J Gastroenterol 1997:32:1013-21.

10. Addolorato G,Stefanini GF, Capristo E,Caputo F,Gasbarini A,Gasbarrini G.Anxiety and depression in adult untreated celiac subjects and in patients affected by Inflammatory Bowel Disease: A Personality 'trait' or a reactive illness? Hepatogastroenterol 1996,43:1513-7.

11. Addolorato G,Capristo E,Ghittoni G etal.Anxiety but not depression decreases in celiac patients after one-year gluten free diet: A Longitudinal Study.Scand J Gastroenterol 2001;5:502-6

12. Kamolz T, Velanovich V, Psychological and Emotional aspects of Gastroesophageal reflux disease. Dis Esophagus 2002; 5:502-6.

13. Carol S North, Barry A Hong, David H Alpers. Relationship of functional gastrointestinal disorders and psychiatric disorders: implications for treatment. World J gastroenterol 2007; 13(4): 2020-2027.

14. Chang L, Toner BB, Fukudo S, Guthrie E, Locke RG, Norton NJ, Sperber AD. Gender, age, society, culture and the patient's perspective in the functional Gastrointestinal disorders. Gastroenterol 2006; 130: 1435-1446.

15. Tally NJ, Zinsmeister AR, Van Dyke,Melton LJ III. Epidemiology of colonic syndromes and IBS. Gastroenterol 1991;101:927-934

16. Drossman DA, Li Z, Andruzzi E, Temple R, Tally Nj, Thompson WG, Whitehead WE et al. us householder survey of functional GI disorders. Prevelance, sociodemography and health impact. Dig Dis Sci 1993:38:1569-1580.

17. Sandler RS. Epidemiology of irritable bowel syndrome in us. Gastroenterol 1990;99;409415

18. Lee OY, Mayerea, Schmulson M, Chang L, et al. Gender differences in IBS symptoms. Am J Gastroenterol2001; 96:2184-2196.

19. Whitehead WE, Cheskin LJ, Heller BR et al. Evidence for exacerbation of IBS symptoms during menses. Gastroenterol 1990;98:1485-1489

(c) The International Journal of Indian Psychology, ISSN 2348-5396 (e)| ISSN: 2349-3429 (p) | 236 


\section{A Study of Psychiatric Morbidity in Patients Attending the Medical Gastro Enterology Unit in a Teaching Hospital}

20. Houghton LA, Lee R, JL, WPJ. The menstrual cycle effects rectal sensitivity in patients with Irritable Bowel Syndrome but not healthy volunteers. Gut 2002;50:471-474

21. Metcalf AM, Philips SF, Zinsmeister AR, McCarty RL et al. Simplified assessment of segmental colonic transit. Gastroenterol 1987;92: 40-47

22. Lempe JW, Fredstrom SB,Slavin JL, Potter JD. Sex difference in colonic function; a randomized trial. Gut 1993; 34:531-536.

23. Simren M, Abrahamsson H, Svedlund J et al. Quality of life in patients with IBS seen in referral centers versus primary care: the impact of gender and predominant bowel pattern. Scand J Gastroenterol 2001; 36:545-552.

24. Corney RH, Stanton R. Physical symptoms severity, psychological and social dysfuntion in a series of out patients with IBS. J psychosom res1990;34:483-491.

25. Locke GR, III, Tally NK, Fett SL, Zinsmeisterar, Melton LJ III. Prevalence and clinical spectrum of gastrointestinal reflux; a population based study in Olmstead county, Minnesota, Gastroenterology 1997; 112; 1448-1456.

26. Eslick GD, Jones M, Talley NJ. Non cardiac chest pain: prevalence,risk factors impact and consulting- a population based study. Ailment Pharmacol Ther 2003; 17: 111-1124

27. Jones LA, Chin LT, Longo DL, Kruisbeek AM. Peripheral Clonal elimination of functional T cells. Science 19990;250;1726-1729

28. Kay L, Jorgensen T. Epidemiology of upper dyspepsia in a random population. Prevalence, incidence, natural history and risk factors, Scand J Gastroenterol 1994;29;22;664-669

29. Chen GD, Hu SW, Chen YC, Lin TL, Lin LY. Prevalence and correlations of anal incontinence and constipation in Taiwanese women. Neurourol Urodyn 2003;22;664-669

30. Wong ML, Wee S, Pin CH, Gan GL, Ye HC. Sociodemographic and lifestyle factors associated with constipation in an elderly Asian community. Am J Gastroenterol 1999;94;1283-1291

31. Wei X, Chen M, Wang J. The epidemiology of irritable bowel syndrome and functional constipation of Guangzhou residents. Zhonghua Nei Ke Za Zhi 2001;40;517-520

32. Rizk DE, Hassan MY, Shaheen H,Cherian JV, Micallef R,Dunn E.The Prevalence and determinants of health care-seeking behaviour for fecal incontinence in multiparous United Arab Emirates females. Dis Colon Rectum 2001;44;1850-1856

33. Toner B, Casati J. Diseases of digestive system,In: Perry N, Johnson SB, Rozensky R, eds. Medical disorders and behavioral applications. Washington, dc: americal psychological association, 2002; 283-305.

How to cite this article: A Ahmed, R Tenali, F Naveed, R Podaralla (2016), A Study of Psychiatric Morbidity in Patients Attending the Medical Gastro Enterology Unit in a Teaching Hospital, International Journal of Indian Psychology, Volume 3, Issue 4, No. 68, ISSN:23485396 (e), ISSN:2349-3429 (p), DIP:18.01.216/20160304, ISBN:978-1-365-39398-3 